\title{
Malnutrition in older adults on financial assistance in an urban Asian country: a mixed methods study
}

\author{
Yu Xuan Koo', Min Li Kang ', Angie Auyong', Glen Zq Liau', Jeremy Hoe', \\ Melody Long', Aaron Koh ${ }^{1}$, Frederick Koh', Rain Liu' ${ }^{2}$ and Gerald Koh ${ }^{3, *}$ \\ 'Yong Loo Lin School of Medicine, National University of Singapore, National University Health System, \\ Singapore: ${ }^{2}$ Institute of Technical Education, Singapore: ${ }^{3}$ Saw Swee Hock School of Public Health, \\ National University of Singapore, National University Health System, Block MD3, \#03-20, 16 Medical Drive, \\ 117597 Singapore
}

Submitted 8 February 2013: Final revision received 20 June 2013: Accepted 5 August 2013: First published online 6 September 2013

\begin{abstract}
Objective: The objectives of the present study were to assess the nutritional status, identify factors for malnutrition risk and evaluate barriers to adequate nutrition among recipients of the Public Assistance (PA) scheme for socio-economically disadvantaged Singaporeans.

Design: Using a cross-sectional study design, we assessed PA recipients' malnutrition risk using the DETERMINE Nutritional Health checklist and the full Mini-Nutritional Assessment (MNA), as well as their nutritional knowledge, co-morbidity burden, depression risk, instrumental and basic activities of daily living (IADL and BADL), and awareness and utilization of available food services. In-depth interviews were also conducted on malnourished individuals (MNA score $<17$ ) to understand barriers to adequate nutrition.

Setting: Homes of community-living older adults and nursing homes of institutionalized older adults.

Subjects: All PA recipients aged $\geq 55$ years in Central Singapore District.

Results: Four hundred and sixty-five of 511 (91.0\%) eligible PA recipients participated in the study. The prevalence of malnutrition in the study population was $2 \cdot 8 \%$. However, $50 \cdot 3 \%$ were at risk of malnutrition. Among community-dwelling respondents, the risk of malnutrition was independently associated with age $>75$ years, currently unmarried, BADL impairment, depression risk and BMI $<19 \cdot 0$ $\mathrm{kg} / \mathrm{m}^{2}$. Qualitative analysis revealed that financial, social and physical barriers and lack of knowledge were the main contributors to poor nutritional status. Only half were aware of subsidized food services and education increased interest in utilizing food services. Among nursing home respondents, those who were BADL impaired were more likely to be at risk of malnutrition.

Conclusions: Among PA recipients, the prevalence of malnutrition is low but the risk of malnutrition is high. Education on adequate nutrition and food services are recommended.
\end{abstract}

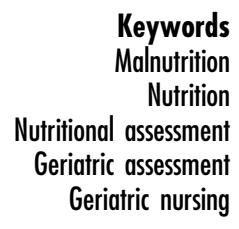

Singapore is an urbanized Asian country with a widening income gap that has resulted in pockets of poverty in the country. The Public Assistance (PA) scheme was started in 1946 for socio-economically disadvantaged citizens and permanent residents who are unable to work due to old age, illness or unfavourable circumstances, and have no means of subsistence or minimal family support $^{(1)}$. PA recipients receive up to $\$ S 400$ (\$US 267) per month and free treatment at public primary care clinics and hospitals. Malnutrition is a cause for concern in the elderly, especially in those of lower socio-economic status. A local study by Yap et al. showed that $30 \cdot 1 \%$ of local community-dwelling Chinese aged above 55 years were at risk of malnutrition, as defined by a DETERMINE Your Nutritional Health checklist score of $\geq 3^{(2)}$. Chan et al. found that $39 \%$ of residents of a local voluntary welfare nursing home were malnourished as defined by a score of $<17$ using the Mini Nutritional Assessment (MNA), and $52 \%$ were found to be underweight as defined by a BMI of $18.5 \mathrm{~kg} / \mathrm{m}^{2}$ or lower ${ }^{(3)}$. In impoverished individuals like PA recipients, however, the prevalence of malnutrition may be even higher than that in the general population due to factors such as greater economic hardship, lack of resources and limited education ${ }^{(4)}$. No previous study has been done on PA recipients to determine their nutritional status. Some of the subsidized 
food services available to PA recipients include meal delivery schemes, meal vouchers to purchase cooked food from establishments and grocery vouchers to purchase food items from grocery stores, all of which have been shown to improve or maintain nutritional risk in older American adults ${ }^{(5)}$. However, the awareness and utilization rate of these services among poor individuals in an urban Asian country have not been previously reported. Hence, we assessed PA recipients' malnutrition risk, nutritional knowledge, co-morbidity burden, depression risk, functional status, and awareness and utilization of available food services. Among malnourished individuals, in-depth interviews were conducted to understand barriers to adequate nutrition.

\section{Materials and methods}

\section{Study population}

Central Singapore District provided the investigators with a master list of all PA recipients under their care $(n 711)$ and sent each household an official letter inviting them to participate prior to the start of the study. The eligibility criteria for study participation were recipients currently receiving PA and aged 55 years or older. The minimum age of 55 years was chosen so our results could be compared with those by Yap et al. ${ }^{(2)}$. The residents of the selected nursing home were included to provide comparison with a similar study done in a local nursing home by Chan et $a l^{(3)}$. Individuals who were noncommunicative (e.g. dementia or dysphasic stroke) were excluded from the study. Eighteen pairs of trained medical student interviewers conducted face-to-face interviews with PA recipients from 5 to 21 January 2010 as the study was part of a community health project within the medical school curriculum of Yong Loo Lin School of Medicine, National University of Singapore. Non-responders were defined as those who were not contactable after three visits on three separate days. Refusals were defined as eligible individuals who refused or failed to complete the survey. A structured quantitative questionnaire was used to record data on the participants' sociodemographic profile, nutritional knowledge, nutritional status, depression risk, co-morbidity burden, functional status, and awareness and utilization of available food services. Individuals identified as malnourished were subsequently invited to participate in a qualitative interview using a guide designed to explore their difficulties in obtaining adequate nutrition.

\section{Assessment tools}

\section{Malnutrition}

Two nutritional assessment tools were used: the DETERMINE Your Nutritional Health checklist and the full MNA. These were chosen to provide a baseline of comparison with previous local studies by Yap et al. and Chan et al. ${ }^{(2,3)}$.
The DETERMINE checklist is a well-used screening tool that detects nutritional risk where a score of $\geq 3$ suggests that the individual is at increased risk of being malnourished $^{(6)}$. The DETERMINE checklist comprises ten questions formulated to identify those with inadequate dietary nutrition according to RDA standards or individuals with underlying medical conditions that affect their health. Questions focus on pre-existing medical issues and difficulties the elderly face which may prevent them from having access to nutrition (e.g. teeth problems or lack of resources to prepare a balanced diet) ${ }^{(6)}$.

The MNA is a nutritional risk assessment tool that has been validated for use on elderly people in both community and nursing home settings ${ }^{(7)}$. The MNA was designed to identify individuals at risk of malnutrition so that nutritional intervention could be administered promptly $^{(7)}$. It comprises four categories: (i) anthropometric measurements; (ii) assessment of an individual's lifestyle, medications and mobility; (iii) dietary questionnaire relating to number of meals, food intake and feeding issues; and (iv) self-perception of nutritional health $^{(7)}$. A score of $<17$ suggests malnutrition, a score of $17-23.5$ suggests risk of malnutrition and a score $\geq 24$ is considered normal. Weight and height were measured using portable weighing machines and measuring tapes respectively. The variation between all weighing machines used was calibrated to within $1 \mathrm{~kg}$ using a standard weight as reference. Respondents with impaired mobility were weighed using a portable seated weighing scale which was transported into their homes. Mid-arm circumference and calf circumference were measured to the nearest centimetre. The MNA score of $<17$ was used to define malnourished individuals who were subsequently invited to participate in the qualitative phase of the study.

\section{Risk factors for malnutrition}

A simple nutritional knowledge screening questionnaire based on the guidelines for healthy eating by the Health Promotion Board of Singapore was developed for the purposes of the present study to assess awareness of nutritional requirements ${ }^{(8)}$. Participants were asked to select the correct number of servings recommended for each of the four food groups (rice and alternatives, fruits, vegetables, and meat and alternatives) out of five given choices (see Appendix 1). One point was awarded for each correct answer. The maximum score was 4 and the minimum was 0 . A score of zero was arbitrarily chosen to indicate poor nutritional knowledge. We opted to use this simple but unvalidated test to assess nutritional knowledge because existing validated measures were lengthy and we wanted to minimize interviewee burden ${ }^{(9)}$. The Charlson Co-morbidity Index was used to assess the co-morbidity burden in the sample population ${ }^{(10)}$. It is recognized as a valid and reliable clinical research tool with high construct validity and is predictive of mortality, disability, readmissions and length of stay. Its test-retest 
reliability is good and inter-rater reliability is moderate to $\operatorname{good}^{(11)}$. The fifteen-item Geriatric Depression Scale - Short Form (GDS-SF) was used to screen for risk of depression ${ }^{(12)}$. The GDS-SF is a validated questionnaire to screen for depression in the general population and in the elderly Chinese population in Singapore ${ }^{(13,14)}$. The GDS-SF has a minimum score of 0 and a maximum of 15 , and a score of 4 and above denotes risk of depression. Functional status was assessed using the Lawton-Brody Scale and the Barthel Index, which are validated research tools to measure instrumental activities of daily living (IADL) and basic activities of daily living (BADL), respectively. Both scales have been previously validated for use in elderly populations and are widely used in research ${ }^{(15-18)}$.

Community-dwelling participants were also surveyed on their awareness and utilization rate of the three subsidized or free food services available locally (i.e. meal delivery services, meal vouchers and grocery vouchers) currently provided by various voluntary welfare organizations. They were also asked about their interest in applying for food services before and after education on these services. Nursing home participants were not interviewed regarding these free food services because all their meals were provided by the residence.

\section{Barriers to adequate nutrition}

In-depth interviews were conducted with respondents identified as malnourished; open-ended prompting questions were asked and participants were allowed to freely express their opinions on the obstacles they faced when obtaining adequate nutrition (see Appendix 2 for the qualitative interview guide). Interviews were conducted in the language and dialect (e.g. Hokkien, Cantonese, etc.) which the participants were conversant with. The interviews were audio-taped and subsequently transcribed into English.

\section{Etbics}

Approval was obtained from the National University of Singapore Institutional Review Board prior to the study. Written consent was obtained before the interview and participants were offered grocery vouchers as tokens of appreciation at the end of the interview.

\section{Data analysis}

Quantitative data analysis was done using PASW Statistics Version 18. Data were entered at the end of each day of field work by each pair of interviewers. The data from each interviewer were manually checked for errors and then collated into a master database. Multiple rounds of manual data cleaning were performed and a final data fidelity check of a random sample of $5 \%$ of data collection forms had an accuracy of $99 \cdot 8 \%$. To determine the factors associated with risk of malnutrition, the full MNA was chosen over the DETERMINE as the main outcome measure, as the latter has not been validated for use in a nursing home setting and the former was found to be superior to the latter in predicting mortality from malnutrition ${ }^{(19)}$. When determining the factors associated with malnutrition, we subsumed malnutrition under risk of malnutrition because the prevalence of malnutrition was very low in our study population. The $\chi^{2}$ test and Fisher's exact test (if $n<5$ in any cell) were used to analyse bivariate associations between categorical variables and the McNemar test was used to compare changes in the proportions interested in food services before and after education. The Pearson correlation coefficient $(r)$ was used to test for collinearity between MNA and BMI scores because BMI is part of the MNA. The cut-off of $P<0 \cdot 10$ was used to decide which factors associated with the risk of malnutrition in community-dwelling respondents would be included in the multivariate logistic regression model. Backward stepwise regression was used to determine the most parsimonious model of factors independently associated with risk of malnutrition. These steps were not performed for nursing home respondents because risk of malnutrition was only associated with one factor in this population.

We used a phenomenological approach involving immersion and crystallization for thematic analysis of the qualitative data ${ }^{(20)}$. Immersion allowed researchers to surround themselves with the qualitative data in order to sensitize them to the tone, mood, range and content of participants' experience. Crystallization reflected the gradual development and clarification of important themes offered by participants. Each interviewer read the transcripts independently first, initially looking for keywords and emerging themes. Subsequently, all interviewers met together to compare, discuss and combine their independent analyses. The final stage of analysis involved examining all interviews with all interviewers until agreement on the key themes and sub-themes was achieved. Although all thirteen malnourished respondents were interviewed, the team felt that data saturation was achieved by the tenth respondent interviewed.

\section{Results}

\section{Quantitative findings}

Among the 711 PA recipients on the master list provided, $551(77 \cdot 5 \%)$ were contactable and the remaining 160 were non-contactable (i.e. non-responders). Of the 551 contactable individuals, forty respondents were not eligible and forty-six refused to participate, resulting in a final sample of 465 individuals (participation rate $=465$ / $(551-40)=91 \cdot 0 \%)$.

\section{Participant characteristics}

The sociodemographic profile of PA recipients dwelling in the community differed greatly from the sociodemographic profile of those living in nursing homes (Table 1). As the profile of community-dwelling and nursing home 
Table 1 Sociodemographic characteristics* of the sample population by community dwelling and nursing home status; recipients of the Public Assistance scheme for socio-economically disadvantaged Singaporeans, Central Singapore District, January 2010

\begin{tabular}{|c|c|c|c|c|c|c|}
\hline \multirow[b]{2}{*}{ Characteristic } & \multicolumn{2}{|c|}{$\begin{array}{c}\text { All } \\
(n \text { 465) }\end{array}$} & \multicolumn{2}{|c|}{$\begin{array}{l}\text { Community } \\
\text { (n 399) }\end{array}$} & \multicolumn{2}{|c|}{$\begin{array}{l}\text { Nursing home } \\
\qquad(n 66)\end{array}$} \\
\hline & $n$ & $\%$ & $n$ & $\%$ & $n$ & $\%$ \\
\hline \multicolumn{7}{|l|}{ Age (years) } \\
\hline $55-64$ & 25 & $5 \cdot 4$ & 23 & $5 \cdot 8$ & 2 & $3 \cdot 0$ \\
\hline $65-74$ & 189 & $40 \cdot 6$ & 175 & $43 \cdot 9$ & 14 & $21 \cdot 2$ \\
\hline $75-84$ & 189 & $40 \cdot 6$ & 176 & $44 \cdot 1$ & 13 & $19 \cdot 7$ \\
\hline $85-94$ & 54 & $11 \cdot 6$ & 22 & $5 \cdot 5$ & 32 & $48 \cdot 5$ \\
\hline $94-104$ & 8 & $1 \cdot 7$ & 3 & $0 \cdot 8$ & 5 & $7 \cdot 6$ \\
\hline Mean & & \multicolumn{2}{|c|}{$74 \cdot 7$} & \multicolumn{2}{|c|}{$83 \cdot 5$} \\
\hline SD & \multicolumn{2}{|c|}{$7 \cdot 8$} & \multicolumn{2}{|c|}{$6 \cdot 6$} & \multicolumn{2}{|c|}{$9 \cdot 8$} \\
\hline \multicolumn{7}{|l|}{ Years on public assistance } \\
\hline Mean & \multirow{2}{*}{\multicolumn{2}{|c|}{$\begin{array}{l}6 \cdot 0 \\
4 \cdot 4\end{array}$}} & & & & \\
\hline SD & & & & & & \\
\hline Gender & & & & & & \\
\hline Male & 283 & $60 \cdot 9$ & 283 & $70 \cdot 9$ & 0 & 0.0 \\
\hline Female & 182 & $39 \cdot 1$ & 116 & $29 \cdot 1$ & 66 & $100 \cdot 0$ \\
\hline Ethnicity & & & & & & \\
\hline Chinese & 432 & $92 \cdot 9$ & 336 & $91 \cdot 7$ & 66 & $100 \cdot 0$ \\
\hline Malay & 14 & $3 \cdot 0$ & 14 & $3 \cdot 5$ & 0 & 0.0 \\
\hline Indian & 16 & $3 \cdot 4$ & 16 & $4 \cdot 0$ & 0 & 0.0 \\
\hline Others & 3 & $0 \cdot 6$ & 3 & $0 \cdot 8$ & 0 & 0.0 \\
\hline Education level & & & & & & \\
\hline No formal qualifications & 339 & $72 \cdot 9$ & 284 & $71 \cdot 2$ & 55 & $83 \cdot 3$ \\
\hline Primary school & 94 & $20 \cdot 2$ & 86 & $21 \cdot \overline{6}$ & 8 & $12 \cdot 1$ \\
\hline Secondary school & 24 & $5 \cdot 2$ & 21 & $5 \cdot 3$ & 3 & $4 \cdot 5$ \\
\hline Above secondary school & 8 & $1 \cdot \overline{7}$ & 8 & $2 \cdot 0$ & 0 & 0.0 \\
\hline Type of housing & & & & & & \\
\hline One-room apartment & 336 & $72 \cdot 3$ & 326 & $84 \cdot 2$ & 0 & 0.0 \\
\hline Two-room apartment & 54 & $11 \cdot 6$ & 52 & $13 \cdot \overline{5}$ & 0 & 0.0 \\
\hline Three-room apartment and above & 9 & 1.9 & 9 & $2 \cdot 3$ & 0 & $0 \cdot 0$ \\
\hline Nursing home & 66 & $14 \cdot 2$ & - & - & 66 & $100 \cdot 0$ \\
\hline Ownership of house & & & & & & \\
\hline Rented & 362 & $77 \cdot 8$ & 362 & $90 \cdot 7$ & 0 & 0.0 \\
\hline Owned & 37 & $8 \cdot 0$ & 37 & $9 \cdot 6$ & 0 & 0.0 \\
\hline Nursing home & 66 & $14 \cdot 2$ & - & - & 66 & $100 \cdot 0$ \\
\hline Marital status & & & & & & \\
\hline Currently married & 46 & $9 \cdot 9$ & 45 & $11 \cdot 3$ & 1 & 1.5 \\
\hline Not married & 419 & $90 \cdot 1$ & 354 & $88 \cdot 7$ & 65 & $98 \cdot 5$ \\
\hline Living arrangement & & & & & & \\
\hline Alone & 208 & $52 \cdot 1$ & 208 & $52 \cdot 1$ & 0 & 0.0 \\
\hline Not alone & 191 & $47 \cdot 9$ & 191 & $47 \cdot 9$ & 66 & $100 \cdot 0$ \\
\hline With family & 88 & $46 \cdot 1$ & 88 & $46 \cdot 1$ & 0 & 0.0 \\
\hline With non-family & 103 & $53 \cdot 9$ & 103 & $53 \cdot 9$ & 66 & $100 \cdot 0$ \\
\hline Preparation of home-cooked meals & & & & & & \\
\hline Self & 264 & $63 \cdot 8$ & 264 & $63 \cdot 8$ & 0 & 0.0 \\
\hline Someone else & 29 & $7 \cdot 0$ & 29 & $7 \cdot 0$ & 66 & $100 \cdot 0$ \\
\hline None & 121 & $30 \cdot 3$ & 121 & $30 \cdot 3$ & 0 & $0 \cdot 0$ \\
\hline Nutrition knowledge & & & & & & \\
\hline 0 & 139 & $29 \cdot 9$ & 121 & $30 \cdot 3$ & 18 & $27 \cdot 3$ \\
\hline$\geq 1$ & 326 & $71 \cdot 1$ & 278 & $69 \cdot 7$ & 48 & $72 \cdot 7$ \\
\hline Instrumental activities of daily living (I & & & & & & \\
\hline Impaired & 225 & $48 \cdot 4$ & 168 & $42 \cdot 1$ & 57 & $86 \cdot 4$ \\
\hline Independent & 240 & $51 \cdot 6$ & 231 & $57 \cdot 9$ & 9 & $13 \cdot 6$ \\
\hline Basic activities of daily living (BADL) & & & & & & \\
\hline Impaired & 158 & $34 \cdot 0$ & 111 & $27 \cdot 8$ & 47 & $71 \cdot 2$ \\
\hline Independent & 307 & $66 \cdot 0$ & 288 & $72 \cdot 2$ & 19 & $28 \cdot 8$ \\
\hline Risk of depression & & & & & & \\
\hline No & 379 & $81 \cdot 5$ & 324 & $81 \cdot 2$ & 55 & $83 \cdot 3$ \\
\hline Yes & 86 & $18 \cdot 5$ & 75 & $18 \cdot 8$ & 11 & $16 \cdot 7$ \\
\hline Charlson co-morbidity score & & & & & & \\
\hline 0 & 218 & $46 \cdot 9$ & 190 & $47 \cdot 6$ & 28 & $42 \cdot 4$ \\
\hline$\geq 1$ & 247 & $53 \cdot 1$ & 209 & $52 \cdot 4$ & 38 & $57 \cdot 6$ \\
\hline BMI $\left(\mathrm{kg} / \mathrm{m}^{2}\right)$ & & & & & & \\
\hline$<19 \cdot 0$ & 119 & $25 \cdot 6$ & 115 & $28 \cdot 8$ & 4 & $6 \cdot 1$ \\
\hline$\geq 19 \cdot 0$ & 346 & $74 \cdot 4$ & 284 & $71 \cdot 2$ & 62 & 93.9 \\
\hline
\end{tabular}

${ }^{*}$ Values are presented as $n$ and $\%$ of the total population reported, unless otherwise stated. 
participants was very different, we have stratified our results by these two groups.

For the community-dwelling group, the mean respondent age was $74 \cdot 7$ (SD 6.6) years and their mean duration on PA was 6.0 ( $\mathrm{SD} 4 \cdot 6$ ) years. The majority were male $(70.9 \%)$, Chinese $(91.7 \%)$, received no formal education $(71 \cdot 2 \%)$, were not currently married (i.e. were divorced, separated or widowed; $88.7 \%$ ), lived alone in one-room apartments (84.2\%) that were mainly rented $(90 \cdot 7 \%)$, and were able to cook their own food $(63 \cdot 8 \%)$. Almost a third $(30 \cdot 3 \%)$ scored zero on the knowledge test, $27 \cdot 8 \%$ were BADL impaired, $42 \cdot 1 \%$ were IADL impaired, $18.8 \%$ were at risk of depression, $52 \cdot 4 \%$ had a Charlson co-morbidity score $\geq 1$ and $28.8 \%$ had a BMI $<19 \cdot 0 \mathrm{~kg} / \mathrm{m}^{2}$.

Compared with the community-dwelling group, the nursing home participants were older at 83.5 (SD 9.8) years but the mean duration on PA was similar at $6 \cdot 0$ (sD 3.5) years; all were female (because of the policy of the nursing home) and of Chinese ethnicity, most had no formal education ( $83.3 \%$ ) and most were not currently married (98.5\%); a similar proportion scored zero on the knowledge test $(27 \cdot 3 \%)$ and were at risk of depression $(16 \cdot 7 \%)$, but the nursing home population were more impaired in their BADL $(71 \cdot 2 \%)$ and IADL $(86 \cdot 4 \%)$, and more had a Charlson co-morbidity score $\geq 1(57 \cdot 6 \%)$. Of note, the nursing home population had a much smaller proportion who had a BMI $<19 \mathrm{~kg} / \mathrm{m}^{2}(6 \cdot 1 \%)$.

\section{Nutritional status}

Using the MNA, the prevalence of malnutrition was $2 \cdot 8 \%(n 13)$ in the community-dwelling population and $1.5 \%(n 1)$ in the nursing home population $(\mathrm{OR}=1.84$; $95 \%$ CI $0.30,11 \cdot 24 ; P=0.703$ ). However, the risk of malnutrition was higher in the nursing home compared with the community-dwelling respondents $(68 \cdot 2 \% v$. $50 \cdot 4 \%, P=0 \cdot 007)$. Using the DETERMINE checklist, the prevalence of risk of malnutrition was $67 \cdot 7 \%$ for the community-dwelling population and $45.5 \%$ in the nursing home population.

\section{Risk factors for malnutrition}

There was little collinearity between BMI and MNA scores as the correlation between the two scores was weak $(r=-0 \cdot 406)$. Cronbach's $\alpha$ for the nutritional knowledge test based on all study respondents was low at 0.34 .

For the community-dwelling group, advanced age (>75 years), currently unmarried, poor nutritional knowledge, BADL impairment, risk of depression and BMI $<19 \cdot 0 \mathrm{~kg} / \mathrm{m}^{2}$ were associated with risk of malnutrition on bivariate analysis (Table 2). For the nursing home group, only BADL impairment was associated with risk of malnutrition on bivariate analysis (Table 2).

For the community-dwelling group, multivariate analysis identified the independent factors for risk of malnutrition as age $>75$ years (adjusted $\mathrm{OR}=1 \cdot 64 ; 95 \%$ CI 1.04, 2.60; $P=0 \cdot 034$ ), currently unmarried (adjusted $\mathrm{OR}=2 \cdot 43$;
95\% CI $1 \cdot 17,5 \cdot 01 ; P=0 \cdot 017$ ), BADL impairment (adjusted $\mathrm{OR}=2 \cdot 20 ; 95 \% \mathrm{CI} 1 \cdot 30,3 \cdot 70 ; P=0 \cdot 003$ ), risk of depression (adjusted $\mathrm{OR}=2 \cdot 66 ; 95 \%$ CI 1.46, 4.85; $P=0.001$ ) and $\mathrm{BMI}<19 \mathrm{~kg} / \mathrm{m}^{2}$ (adjusted $\mathrm{OR}=9 \cdot 71$; $95 \%$ CI $5 \cdot 46,17 \cdot 2 ; P<0 \cdot 001$ ). Poor nutritional knowledge was not found to be significant factor for risk of malnutrition on multivariate analysis.

\section{Food services}

The majority of respondents were aware of the food services available to them: $65 \cdot 8 \%, 57 \cdot 4 \%$ and $54 \cdot 8 \%$ of the study population were aware of meal delivery, meal voucher and grocery voucher services, respectively. However, only $20 \cdot 8 \%, 31 \cdot 6 \%$ and $38 \cdot 3 \%$ were receiving meal delivery services, meal vouchers and grocery vouchers, respectively. After education on the availability and details of these services, interest in applying increased for meal delivery from $25 \cdot 2 \%$ to $28 \cdot 2 \%(P=0 \cdot 041)$; for meal vouchers from $46 \cdot 8 \%$ to $57 \cdot 7 \%(P<0 \cdot 001)$; and for grocery vouchers from $67 \cdot 8 \%$ to $79 \cdot 9 \%(P<0 \cdot 001$; Table 3$)$.

\section{Qualitative findings}

Thirteen community-dwelling malnourished respondents were interviewed and the main barriers to adequate nutrition identified were financial, social and physical barriers, and lack of knowledge.

\section{Financial barriers}

Due to their tight financial situation, malnourished PA recipients were primarily concerned with the quantity of food they could obtain from their fixed allowance rather than food quality or achieving a balanced diet (Quote 1, Table 4). For example, they would prefer to buy canned and preserved vegetables and condensed milk instead of fresh vegetables and milk because the latter are more expensive and perishable. Even if they were moved to consider nutrition as a factor in their purchases, fiscal constraints prevented them from doing so (Quote 2, Table 4).

\section{Social barriers}

Malnourished PA recipients faced many social issues such as depression and loneliness (Quote 3, Table 4) which contributed to lack of appetite, mealtimes no longer being a social activity and decreased attention to the meals. Moreover, their isolation and hence poor support network further exacerbated the situation, especially for those with impaired mobility who had no caregiver available to shop or cook for them (Quote 4, Table 4).

\section{Physical barriers}

Respondents who had issues with mobility or IADL (as defined by the Lawton-Brody Scale) found it difficult to utilize meal or food vouchers as this entailed reaching nearby food establishments or grocery outlets to purchase 
Table 2 Bivariate comparisons of demographic characteristics of participants who are healthy against those at risk of malnutrition or malnourished, as measured by Mini-Nutritional Assessment score, by community dwelling and nursing home status; recipients of the Public Assistance scheme for socio-economically disadvantaged Singaporeans, Central Singapore District, January 2010

\begin{tabular}{|c|c|c|c|c|c|c|c|c|c|c|c|c|c|c|}
\hline \multirow[b]{3}{*}{ Characteristic } & \multicolumn{7}{|c|}{ Community ( $n$ 399) } & \multicolumn{7}{|c|}{ Nursing home $(n 66)$} \\
\hline & \multicolumn{2}{|c|}{$\begin{array}{l}\text { At risk or } \\
\text { malnourished }\end{array}$} & \multicolumn{2}{|c|}{ Healthy } & \multirow{2}{*}{$\begin{array}{l}\text { Unadjusted } \\
\text { OR }\end{array}$} & \multirow[b]{2}{*}{$95 \% \mathrm{Cl}$} & \multirow[b]{2}{*}{$P$ value } & \multicolumn{2}{|c|}{$\begin{array}{l}\text { At risk or } \\
\text { malnourished }\end{array}$} & \multicolumn{2}{|c|}{ Healthy } & \multirow{2}{*}{$\begin{array}{l}\text { Unadjusted } \\
\text { OR }\end{array}$} & \multirow[b]{2}{*}{$95 \% \mathrm{Cl}$} & \multirow[b]{2}{*}{$P$ value } \\
\hline & $n$ & $\%$ & $n$ & $\%$ & & & & $n$ & $\%$ & $n$ & $\%$ & & & \\
\hline Total & 201 & $50 \cdot 4$ & 198 & $49 \cdot 6$ & - & - & - & 45 & $68 \cdot 2$ & 21 & $31 \cdot 8$ & - & - & - \\
\hline \multicolumn{15}{|l|}{ Age } \\
\hline $\begin{array}{l}>75 \text { years } \\
\leq 75 \text { years }\end{array}$ & $\begin{array}{r}109 \\
92\end{array}$ & $\begin{array}{l}59 \cdot 2 \\
42 \cdot 8\end{array}$ & $\begin{array}{r}75 \\
123\end{array}$ & $\begin{array}{l}40 \cdot 8 \\
57 \cdot 2\end{array}$ & $\begin{array}{l}1.38 \\
1.00\end{array}$ & $\begin{array}{c}1 \cdot 14,1 \cdot 68 \\
\text { Ref. }\end{array}$ & 0.001 & $\begin{array}{r}36 \\
9\end{array}$ & $\begin{array}{l}73 \cdot 5 \\
52 \cdot 9\end{array}$ & $\begin{array}{r}13 \\
8\end{array}$ & $\begin{array}{l}26 \cdot 5 \\
47 \cdot 1\end{array}$ & $\begin{array}{l}1 \cdot 39 \\
1 \cdot 00\end{array}$ & $\begin{array}{c}0 \cdot 86,2 \cdot 24 \\
\text { Ref. }\end{array}$ & $0 \cdot 117$ \\
\hline \multicolumn{15}{|l|}{ Gender } \\
\hline Male & 137 & $48 \cdot 4$ & 146 & $51 \cdot 6$ & $0 \cdot 88$ & $0 \cdot 72,1 \cdot 08$ & $0 \cdot 220$ & 0 & $0 \cdot 0$ & 0 & 0.0 & - & - & - \\
\hline Female & 64 & $55 \cdot 2$ & 52 & $44 \cdot 8$ & 1.00 & Ref. & & 45 & $68 \cdot 2$ & 21 & $31 \cdot 8$ & - & - & \\
\hline \multicolumn{15}{|l|}{ Ethnicity } \\
\hline Chinese & 181 & $49 \cdot 5$ & 185 & $50 \cdot 5$ & $0 \cdot 82$ & $0 \cdot 61,1 \cdot 10$ & $0 \cdot 220$ & 45 & $68 \cdot 2$ & 21 & $31 \cdot 8$ & - & - & - \\
\hline Others & 20 & $60 \cdot 6$ & 13 & $39 \cdot 4$ & $1 \cdot 00$ & Ref. & & 0 & $0 \cdot 0$ & 0 & $0 \cdot 0$ & - & - & \\
\hline \multicolumn{15}{|l|}{ Education level } \\
\hline No formal qualifications & 142 & $50 \cdot 0$ & 142 & $50 \cdot 0$ & 0.98 & $0 \cdot 79,1 \cdot 21$ & $0 \cdot 813$ & 35 & $63 \cdot 6$ & 20 & $36 \cdot 4$ & $0 \cdot 70$ & $0.53,0.92$ & $0 \cdot 153$ \\
\hline Primary school and above & 59 & $51 \cdot 3$ & 56 & $48 \cdot 7$ & $1 \cdot 00$ & Ref. & & 10 & $90 \cdot 9$ & 1 & $9 \cdot 1$ & 1.00 & Ref. & \\
\hline \multicolumn{15}{|l|}{ Type of housing } \\
\hline One-room apartment & 171 & $50 \cdot 9$ & 165 & $49 \cdot 1$ & 1.07 & $0 \cdot 81,1 \cdot 41$ & 0.633 & 45 & $68 \cdot 2$ & 21 & $31 \cdot 8$ & - & - & - \\
\hline Two-room apartment and above & 30 & $47 \cdot 6$ & 33 & $52 \cdot 4$ & $1 \cdot 00$ & Ref. & & - & - & - & - & - & - & \\
\hline \multicolumn{15}{|l|}{ Ownership of house } \\
\hline Rented & 181 & $50 \cdot 0$ & 181 & $50 \cdot 0$ & 0.93 & $0 \cdot 68,1 \cdot 27$ & 0.639 & 45 & $68 \cdot 2$ & 21 & $31 \cdot 8$ & - & - & - \\
\hline Owned & 20 & $54 \cdot 1$ & 17 & $45 \cdot 9$ & $1 \cdot 00$ & Ref. & & - & - & - & - & - & - & \\
\hline \multicolumn{15}{|l|}{ Marital status } \\
\hline Currently married & 16 & $35 \cdot 6$ & 29 & $64 \cdot 4$ & 0.68 & $0 \cdot 45,1 \cdot 02$ & 0.035 & 0 & 0.0 & 0 & $0 \cdot 0$ & - & - & - \\
\hline Not married & 185 & $52 \cdot 3$ & 169 & $47 \cdot 7$ & $1 \cdot 00$ & Ref. & & 45 & $68 \cdot 2$ & 21 & $31 \cdot 8$ & - & - & \\
\hline \multicolumn{15}{|l|}{ Currently living } \\
\hline Alone & 104 & $50 \cdot 0$ & 104 & $50 \cdot 0$ & 0.99 & $0 \cdot 81,1 \cdot 20$ & 0.875 & 45 & $68 \cdot 2$ & 21 & $31 \cdot 8$ & - & - & - \\
\hline Not alone & 97 & $50 \cdot 8$ & 94 & $49 \cdot 2$ & $1 \cdot 00$ & Ref. & & 0 & $0 \cdot 0$ & 0 & $0 \cdot 0$ & - & - & \\
\hline \multicolumn{15}{|l|}{ Prepares home-cooked meals } \\
\hline Yes & 144 & $49 \cdot 1$ & 149 & $50 \cdot 9$ & 0.91 & $0 \cdot 74,1 \cdot 13$ & 0.414 & - & - & - & - & - & - & - \\
\hline No & 57 & $53 \cdot 8$ & 49 & $46 \cdot 2$ & $1 \cdot 00$ & Ref. & & 45 & $68 \cdot 2$ & 21 & $31 \cdot 8$ & - & - & \\
\hline Duration on public assistance & & & & & & & & & & & & & & \\
\hline$\leq 7$ years & 137 & $47 \cdot 7$ & 150 & $52 \cdot 3$ & 0.84 & $0.68,1.02$ & 0.091 & 32 & $65 \cdot 3$ & 17 & $34 \cdot 7$ & 0.85 & $0 \cdot 61,1 \cdot 19$ & 0.548 \\
\hline$>7$ years & 64 & $57 \cdot 1$ & 48 & $42 \cdot 9$ & 1.00 & Ref. & & 13 & $76 \cdot 5$ & 4 & $23 \cdot 5$ & 1.00 & Ref. & \\
\hline Nutrition knowledge & & & & & & & & & & & & & & \\
\hline 0 & 71 & $58 \cdot 7$ & 50 & $41 \cdot 3$ & $1 \cdot 26$ & $1.03,1.53$ & 0.029 & 12 & $66 \cdot 7$ & 6 & $33 \cdot 3$ & 0.97 & $0 \cdot 66,1 \cdot 42$ & $0 \cdot 871$ \\
\hline$>0$ & 130 & $46 \cdot 8$ & 148 & $53 \cdot 2$ & $1 \cdot 00$ & Ref. & & 33 & $68 \cdot 8$ & 15 & $31 \cdot 3$ & $1 \cdot 00$ & Ref. & \\
\hline Instrumental activities of daily living & & & & & & & & & & & & & & \\
\hline Impaired & 93 & $55 \cdot 4$ & 75 & $44 \cdot 6$ & $1 \cdot 18$ & $0.98,1.44$ & 0.090 & 40 & $70 \cdot 2$ & 17 & $29 \cdot 8$ & $1 \cdot 26$ & $0 \cdot 69,2 \cdot 32$ & 0.450 \\
\hline Independent & 108 & $46 \cdot 8$ & 123 & $53 \cdot 2$ & $1 \cdot 00$ & Ref. & & 5 & $55 \cdot 6$ & 4 & $44 \cdot 4$ & $1 \cdot 00$ & Ref. & \\
\hline
\end{tabular}


food (Quotes 4 and 5, Table 4). Visual impairment is common among the elderly and this impairs their ability to cook (Quote 6, Table 4). Other health problems such as poor dentition which limits the choice of foods they are able to consume (Quote 7, Table 4) and medical illnesses which cause loss of appetite (Quote 8, Table 4) exacerbated malnutrition.

\section{Lack of knowledge}

Some respondents were not aware of their own poor nutritional status (Quote 9, Table 4), let alone know what was adequate nutrition. Others were not aware of the various available food services open to them, let alone utilize them.

\section{Discussion}

Although the prevalence of malnutrition among community-dwelling and nursing home PA recipients was low, the prevalence of risk of malnutrition was high, with the nursing home population having a higher prevalence. Among community-dwelling respondents, malnutrition risk was independently associated with older age, being unmarried, BADL impairment, depression risk and low BMI; only half were aware of subsidized food services and only about a third were actually utilizing these services; education on these subsidized food services increased interest in applying for them. Among nursing home PA recipients, only BADL impairment was associated with malnutrition risk. Among malnourished PA recipients, impediments to adequate nutrition included financial, social and physical barriers, and poor knowledge about adequate nutrition.

The prevalence of malnutrition in our communitydwelling PA population was comparable to that found in previous studies on community-dwelling elderly in other countries $^{(21-24)}$. However, the prevalence of malnutrition in our nursing home PA population (1.5\%) was much lower than in the 180-bed nursing home located in singapore assessed by Chan et al. $(39 \%)^{(3)}$. This is an interesting finding, which may be attributed to the availability of standardized meals prepared at the nursing home in our study. With reference to the MNA, most nursing home PA recipients would have access to three full meals, consisting of dairy products, proteins, fruits and vegetables. This would have scored the nursing home PA population higher on the MNA. The difference in demographics between the female-only nursing home in our study and the mixed-gender nursing home studied by Chan et al. $^{(3)}$ could also have accounted for some difference in the reported values. Nevertheless, both nursing homes were managed by voluntary organizations and were culturally similar. Compared with the general community-dwelling Singapore population aged $\geq 55$ years who were at risk of malnutrition using DETERMINE 
Table 3 Effect of education on interest in applying for food services among recipients of the Public Assistance scheme for socioeconomically disadvantaged Singaporeans, Central Singapore District, January 2010

\begin{tabular}{|c|c|c|c|c|c|c|c|}
\hline \multirow[b]{3}{*}{ Pre-education } & \multicolumn{6}{|c|}{ Post-education } & \multirow[b]{3}{*}{$P$ value } \\
\hline & \multicolumn{2}{|c|}{ Total } & \multicolumn{2}{|c|}{ Yes } & \multicolumn{2}{|c|}{ No } & \\
\hline & $n$ & $\%$ & $n$ & $\%$ & $n$ & $\%$ & \\
\hline \multicolumn{8}{|c|}{ Interest in meal delivery services } \\
\hline No & 225 & $74 \cdot 8$ & 14 & $4 \cdot 7$ & 211 & $70 \cdot 1$ & 0.041 \\
\hline Yes & 76 & $25 \cdot 2$ & 71 & $23 \cdot 6$ & 5 & $1 \cdot 7$ & \\
\hline Total & 301 & $100 \cdot 0$ & 85 & $28 \cdot 2$ & 216 & $71 \cdot 8$ & \\
\hline \multicolumn{8}{|c|}{ Interest in meal vouchers } \\
\hline No & 141 & $53 \cdot 2$ & 33 & $12 \cdot 5$ & 108 & $40 \cdot 8$ & $<0.001$ \\
\hline Yes & 124 & $46 \cdot 8$ & 120 & $45 \cdot 3$ & 4 & 1.5 & \\
\hline Total & 265 & $100 \cdot 0$ & 153 & $57 \cdot 7$ & 112 & $42 \cdot 3$ & \\
\hline \multicolumn{8}{|c|}{ Interest in grocery vouchers } \\
\hline No & 77 & $32 \cdot 2$ & 30 & $12 \cdot 6$ & 47 & $19 \cdot 7$ & $<0.001$ \\
\hline Yes & 162 & $67 \cdot 8$ & 161 & $67 \cdot 4$ & 1 & 0.4 & \\
\hline Total & 239 & $100 \cdot 0$ & 191 & $79 \cdot 9$ & 48 & $20 \cdot 1$ & \\
\hline
\end{tabular}

Significant $P$ values for the change in the percentage interested, pre-education $v$. post-education (bold values), are indicated in bold font.

Table 4 Quotations from malnourished individuals in receipt of the Public Assistance scheme for socio-economically disadvantaged Singaporeans, Central Singapore District, January 2010

\begin{tabular}{|c|c|c|}
\hline Quote no. & Respondent profile & Quotation \\
\hline \multicolumn{3}{|c|}{ Financial difficulties } \\
\hline 1. & $\begin{array}{l}\text { 75-year-old Chinese man living } \\
\text { alone (R1) }\end{array}$ & $\begin{array}{l}\text { 'I rarely take any fruits and milk products... What is important is that I } \\
\text { can have three meals a day.' }\end{array}$ \\
\hline 2. & $\begin{array}{l}\text { 68-year-old Chinese man living } \\
\text { alone (R2) }\end{array}$ & $\begin{array}{l}\text { 'Money! Money is the problem. I don't have enough money, how do I } \\
\text { buy the kind of food I want?' }\end{array}$ \\
\hline \multicolumn{3}{|r|}{ 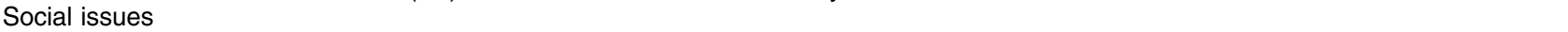 } \\
\hline 3. & $\begin{array}{l}\text { 82-year-old Chinese lady living } \\
\text { alone (R3) }\end{array}$ & $\begin{array}{l}\text { 'I feel sad ... not satisfied ... very bored... I feel I have very few } \\
\text { friends ... I almost never feel happy.' }\end{array}$ \\
\hline 4. & $\begin{array}{l}\text { 73-year-old Chinese lady living } \\
\text { alone (R4) }\end{array}$ & $\begin{array}{l}\text { 'No [l'm not interested in meal voucher schemes]. I can't walk, and I } \\
\text { don't have friends who are willing to help me [to buy food] that often.' }\end{array}$ \\
\hline \multicolumn{3}{|c|}{ Physical barriers } \\
\hline 5. & $\begin{array}{l}\text { 73-year-old Chinese lady living } \\
\text { alone (R4) }\end{array}$ & $\begin{array}{l}\text { 'I can't get out to buy food. If I could go out myself, I could buy food } \\
\text { with vitamins and better nutrients, then I would be healthier.' }\end{array}$ \\
\hline 6. & $\begin{array}{l}\text { 82-year-old Chinese lady living } \\
\text { alone with dense bilateral } \\
\text { cataracts (R3) }\end{array}$ & $\begin{array}{l}\text { 'Sometimes I can't see what I'm doing. So I can't fry vegetables, but } \\
\text { I still can boil noodles.' }\end{array}$ \\
\hline 7. & $\begin{array}{l}\text { 82-year-old edentulous Chinese } \\
\text { lady living alone who cannot } \\
\text { afford dentures (R3) }\end{array}$ & $\begin{array}{l}\text { 'The vegetables they [meal delivery service] give are very hard. } \\
\text { Because I no longer have teeth, I can't chew them. I have to re-cook } \\
\text { them to make them softer.' }\end{array}$ \\
\hline 8. & $\begin{array}{l}\text { 82-year-old Chinese lady living } \\
\text { alone (R3) }\end{array}$ & 'Sometimes I don't have [any] appetite because I'm not feeling well.' \\
\hline \multicolumn{3}{|c|}{ Lack of knowledge } \\
\hline 9. & $\begin{array}{l}\text { 68-year-old Chinese man living } \\
\text { alone (R2) }\end{array}$ & 'I have no problems with nutrition ... there is nothing wrong with me.' \\
\hline
\end{tabular}

$\mathrm{R}$, respondent.

score as determined by Yap et al. $(30 \cdot 1 \%)^{(2)}$, the prevalence of risk of malnutrition in our community-dwelling PA population was two times higher at $67 \cdot 7 \%$ using the same tool. When compared with a similar socioeconomically disadvantaged population in Taiwan where the prevalence of risk of malnutrition was $37 \cdot 9 \%$ using the $\mathrm{MNA}^{(24)}$, the prevalence of risk of malnutrition in our community-dwelling PA population was higher at $68 \cdot 2 \%$.

The factors identified to be independent factors associated with risk of malnutrition were similar to those from previous studies. Advanced age is associated with risk of malnutrition due to physiological changes related to senescence and higher incidence of chronic illnesses which impair appetite, increase nutritional needs and contribute to functional dependence. Moreover, older individuals have lower financial and social resources to obtain adequate nutrition. Social factors such as being unmarried have also been shown to contribute to malnutrition risk ${ }^{(21)}$. The lack of a spouse not only deprives people of companionship at meals which are usually communal social events, but may also discourage domestic food preparation and promote greater reliance on less nutritious pre-processed food options. Functional impairment is commonly associated with risk of malnutrition and 
is related to feeding problems and poor mobility, limiting one's ability to cook and shop ${ }^{(21,24)}$. Depression is also a known contributory factor to risk of malnutrition ${ }^{(24)}$ and this may be explained by reduced appetite and decreased motivation to self-care in depressed individuals. A low BMI was also associated with malnutrition risk but this is probably a result of chronic malnutrition rather than a causative factor.

The suboptimal awareness of PA recipients about food services available and the increased interest of the respondents in these services after education suggest that much benefit may be derived from better education of PA recipients on the food services provided by voluntary welfare organizations. It may be helpful to tailor the various types of food services to the needs of recipients and this may also contribute to better resource utilization. For example, individuals with poor mobility would more likely benefit more from meal delivery services than food or grocery vouchers as they have problems reaching nearby food establishments and grocery outlets.

The limitations of the study include the lack of objective measures of nutritional status such as biochemical tests and dietary assessments. Our study was a crosssectional one, so causality cannot be inferred. Our nutrition knowledge test was unvalidated and it had a low Cronbach's $\alpha$ in our study population, which suggests its internal validity is limited. Participants' answers to the nutritional knowledge test were based on their understanding of the dimension of a serving size. Interviewer's description of a serving size could have been interpreted differently by participants and supplemental visual aids could have been useful in ensuring that the PA recipients had a more uniform understanding of a serving size. As the study was conducted on PA recipients within the central district of Singapore, results should not be generalized to other areas in Singapore or other countries with different socio-economic status or financial assistance programmes. The sample size in the nursing home population was small and this is probably a major reason why only one factor was found to be associated with malnutrition risk. Moreover, as the nursing home population was from only one institution and conducted in an all-female nursing home, our nursing home results cannot be extrapolated beyond our study. Nevertheless, the strength of our study is its use of a mixed method study design to quantify the nutritional status and contextualize the barriers to adequate nutrition faced by socio-economically challenged persons in an urbanized Asian country.

\section{Conclusion}

Although the prevalence of malnutrition among communitydwelling and nursing home Singaporeans on public financial assistance was low, the prevalence of risk of malnutrition was high, with the nursing home population having a higher prevalence. To improve their nutritional status, we need to focus on addressing functional disability, depression and financial barriers, and better educating these elderly PA recipients on adequate nutrition and on available subsidized food services.

\section{Acknowledgements}

Sources of funding: This project was funded by the Central Singapore Community Development Council and Heartware Network, Singapore. The funders had no role in the design, analysis or writing of this article. Conflicts of interest: The authors declare no conflict of interest. Authors' contributions: X.Y.K. and M.L.K. contributed equally to the study. All authors contributed to the study design, data collection, statistical analysis, discussion and writing of the final manuscript. Acknowledgements: The authors thank the Central Singapore Community Development Council for providing the list of PA/SG clients, from which data were obtained. They also thank the students of 2010 Community Health Project Group 1 and the Institute of Technical Education Nursing for assisting in the study.

\section{References}

1. Ministry of Social and Family Development (2012) Permanently Unable to Work (Also known as Public Assistance). Version current 12 June 2012. http://app.msf.gov.sg/ComCare/ FindTheAssistanceYouNeed/PermanentlyUnabletoWork.aspx (accessed August 2013).

2. Yap KB, Niti M \& Ng TP (2007) Nutrition screening among community-dwelling older adults in Singapore. Singapore Med J 48, 911-916.

3. Chan M, Lim YP, Ernest A et al. (2010) Nutritional assessment in an Asian nursing home and its association with mortality. J Nutr Health Aging 14, 23-28.

4. Moshfegh AJ (2007) Research to advance understanding of the interrelationship of poverty and nutrition. J Am Diet Assoc 107, 1882-1885.

5. Keller HH (2006) Meal programs improve nutritional risk: a longitudinal analysis of community-living seniors. $\mathrm{J} \mathrm{Am}$ Diet Assoc 106, 1042-1048.

6. Posner BM, Jette AM, Smith KW et al. (1993) Nutrition and health risks in the elderly: the nutrition screening initiative. Am J Public Health 83, 972-978.

7. Guigoz Y \& Vellas B (1998) The Mini-Nutritional Assessment for grading the nutritional state of elderly patients: presentation of the MNA, history and validation. Nestle Nutr Workshop Ser Clin Perform Programme 1, 3-11.

8. Health Promotion Board (2010) Food Pyramid. Version current 3 April 2010. http://internet-stg.hpb.gov.sg/foodforhealth/article.aspx?id=2638 (accessed February 2011).

9. Hendrie GA, Coveney J \& Cox D (2008) Exploring nutrition knowledge and the demographic variation in knowledge levels in an Australian community sample. Public Health Nutr 11, 1365-1371.

10. Charlson ME, Pompei P, Ales KL et al. (1987) A new method of classifying prognostic comorbidity in longitudinal studies: development and validation. J Chronic Dis 40, 373-383.

11. De Groot V, Beckerman H, Lankhorst GJ et al. (2003) How to measure comobidity: a critical review of available methods. J Clin Epidemiol 56, 221-229. 
12. Marc LG, Raue PJ \& Bruce ML (2008) Screening performance of the 15-item geriatric depression scale in a diverse elderly home care population. Am J Geriatr Psychiatry 16, 914-921.

13. De Craen AJ, Heeren TJ \& Gussekloo J (2003) Accuracy of the 15 item Geriatric Depression Scale in a community sample of oldest old. Int J Geriatr Psychiatry 18, 63-66.

14. Lim PP, Ng LL, Chiam PC et al. (2000) Validation and comparison of three brief depression scales in an elderly Chinese population. Int J Geriatr Psychiatry 15, 824-830.

15. Gresham GE, Alexander D, Bishop DS et al. (1997) American Heart Association Prevention Conference. IV. Prevention and Rehabilitation of Stroke. Rehabilitation Stroke 28, 1522-1526.

16. Lawton MP \& Brody EM (1969) Assessment of older people: self-maintaining and instrumental activities of daily living. Gerontologist 9, 179-186.

17. Graf C (2008) The Lawton instrumental activities of daily living scale. Am J Nurs 108, 52-62.

18. Sainsbury A, Seebass G, Bansal A et al. (2005) Reliability of the Barthel Index when used with older people. Age Ageing 34, 228-232.

19. Beck AM, Ovesen L \& Osler M (1999) The 'Mini Nutritional Assessment' (MNA) and the 'Determine Your Nutritional Health' Checklist (NSI Checklist) as predictors of morbidity and mortality in an elderly Danish population. BrJ Nutr $\mathbf{8 1}$, 31-36.

20. Crabtree BF \& Miller WL (editors) (1999) Doing Qualitative Research. Thousand Oaks, CA: Sage Publications.

21. Han Y, Li S \& Zheng Y (2009) Predictors of nutritional status among community-dwelling older adults in Wuhan, China. Public Health Nutr 12, 1189-1196.

22. Tsai AC, Ho CS \& Chang MC (2008) Assessing the prevalence of malnutrition with the Mini Nutritional Assessment (MNA) in a nationally representative sample of elderly Taiwanese. J Nutr Health Aging 12, 239-243.

23. Cuervo M, García A, Ansorena D et al. (2009) Nutritional assessment interpretation on 22,007 Spanish communitydwelling elders through the Mini Nutritional Assessment test. Public Health Nutr 12, 82-90.

24. Chen CC (2005) A framework for studying the nutritional health of community-dwelling elders. Nurs Res $\mathbf{5 4}$, $13-21$.

\section{Appendix 1}

\section{Nutritional knowledge test}

1. How many servings of rice and/or alternatives (e.g. noodles, potatoes, etc.) do you think you should consume every day?
A. 0 servings
B. 1-3 servings
C. $3-5$ servings
D. 5-7 servings
E. $>7$ servings

2. How many servings of fruits do you think you should consume every day?
A. 0 servings
B. $0 \cdot 5-1$ servings
C. $1 \cdot 5-2$ servings
D. $2 \cdot 5-3$ servings
E. $>3$ servings

3. How many servings of vegetables do you think you should consume every day?
A. 0 servings
B. $0 \cdot 5-1$ servings
C. $1 \cdot 5-2$ servings
D. $2 \cdot 5-3$ servings
E. $>3$ servings

4. How many servings of meat and/or alternatives (e.g. milk products, soya products, pulses, etc.) do you think you should consume every day?
A. 0 servings
B. $0 \cdot 5-1$ servings
C. 1-2 servings
D. 2-3 servings
E. $>3$ servings

(The correct answers for questions 1 to 4 are D, C, C and D, respectively. Cronbach's $\alpha$ for the nutritional knowledge test based on all study participants was low at $0 \cdot 34$.)

\section{Appendix 2}

\section{Qualitative interview guide}

1. Do you think/feel you are malnourished?

2. What do you think adequate/good nutrition is?

3. How often do you meet this level of nutrition? Please detail.

4. Do you feel your diet is inadequate and how?

5. What do you think are problems/barriers you face in obtaining adequate nutrition? Prompts:

a. Do you face financial difficulties in obtaining food?

b. Does your environment/people around you/situation pose inconveniences or problems for you to obtain adequate nutrition?

c. Do you face any other problems or inconveniences in obtaining adequate nutrition?

d. Do you prepare your meals? If not, why? Who does so for you?

6. If you were told that your diet was deficient,

e. Would you feel there is a need to correct this?

f. Would you know how to correct this/How would you correct this? 